\title{
Regularities of oilfield pipeline leak rate variation in time
}

\author{
I. S. Sivokon and N. N. Andreev* \\ A. N. Frumkin Institute of Physical Chemistry and Electrochemistry, Russian Academy \\ of Sciences, Leninskii pr. 31, Moscow, 119071 Russian Federation \\ *E-mail: n.andreev@mail.ru
}

\begin{abstract}
The dependence of the rate of corrosion-related oilfield pipeline leaks on operation time is analyzed. It is shown theoretically that the oilfield pipeline leak rate first increases and then decreases after reaching a maximum. The validity of this conclusion is demonstrated using data on the leak rate at various oilfield pipeline types.
\end{abstract}

Key words: oilfield pipelines, leak rate, corrosion inhibition.

Received: January 31, 2014.

doi: $\underline{10.17675 / 2305-6894-2014-3-2-101-104}$

Damage of oilfield pipeline (OFP) integrity due to inside and/or outside corrosion is a frequent reason of accidents [1]. The efficiency of anti-corrosion protective measures that are a prerequisite of large-scale extraction, transportation and processing of crude hydrocarbons, is estimated by various indicators, such as "time to first repair", "critical operation period", etc. [2]. One of important criteria is the rate of OFP leaks, i.e., facts of their depressurization due to penetrating corrosion damage. It is implied that this parameter increases from year to year if no protective measures are taken, and the older a pipe, the more frequently the leaks occur. A decrease in the leak rate or its stabilization in OFPs of a certain type is commonly recognized as a result of protection measures (e.g., by means of corrosion inhibitors) or a decrease in medium corrosivity.

This paper aims at analyzing the validity of these conclusions.

It is easy to show that the intuitively obvious monotonous increase in pipe leak frequency with time is not observed under real conditions.

Let us consider a corroding surface of a metal pipe as a combination of areas that are characterized (because of differences in the medium composition, operation conditions, metallurgical inhomogeneity, etc.) by different thinning rates $(K)$ due to inside and outside corrosion.

Let us note that there are no areas with infinitely high $K$ values that would result in instantaneous pipe perforation. In fact, the pipe remains whole at least for some time after the start of pipe operation.

Areas with $K=0$ are also missing. Though the $K$ value is vary small in some areas, it still differs from zero. At least the entire inside pipe surface is subject to corrosion at various rates. 
Between an infinitely high and zero thinning rates, there is the range of $K$ values responsible for OFP leaks. Thus, the distribution of the number of areas by corrosion rates is characterized by one or more maxima.

The number of areas with $\mathrm{K}$ values in the range from $K_{1}$ to $K_{2}$ expressed in mm per year characterizes the number of perforations of a pipe $L \mathrm{~mm}$ thick during the period from $L / K_{1}$ to $L / K_{2}$ years, i.e., the frequency of leaks. The extremal distribution of the number of pipe surfaces by thinning rates predetermines a similar time dependence of the frequency of new leaks. The frequency of leaks of a certain OFP type will grow during some initial period. However, as some maximum has been reached, it will decrease inevitably. This decrease is not related to changes in the pipe operation conditions.

This conclusion is paradoxical at first sight but it agrees well with the experience in OFP operation. Let us consider the leak data for the main OFP types at TNK-BP's BU "Orenburg-Saratov" (PU "Center" and "South") for 2004. Tables 1 and 2 present data on the number of leaks per kilometer of oil gathering systems, pressurized oil pipe lines, lowand high-pressure water lines, and flow lines, for pipes with various operation lives. Nearly all the incidents were due to local corrosion. The resulting holes were repaired using pipe clamps or pipe sections. It is important that no activities on protection from inside corrosion were performed at these OFPs until 2004. The outside OFP protection was generally limited to a poor-quality film coating applied under field conditions and hence bearing numerous defects.

Table 1. Leak data for the main OFP types belonging to TNK-BP's BU “Orenburg-Saratov" (PU "Center") for 2004.

Number of leaks per $1 \mathrm{~km}$ of OFP for pipes operated for:

\begin{tabular}{lccccc}
\cline { 2 - 6 } OFP type & up to $\mathbf{5}$ years & $\mathbf{5}$ to 10 years & $\mathbf{1 0}$ to 15 years & $\mathbf{1 5}$ to 20 years & $\begin{array}{c}\text { above 20 } \\
\text { years }\end{array}$ \\
\hline $\begin{array}{l}\text { Oil gathering } \\
\text { systems }\end{array}$ & 0.23 & 1.23 & 2.65 & 0.28 & 0.60 \\
$\begin{array}{l}\text { Pressurized } \\
\text { pipelines }\end{array}$ & 0.01 & 0.21 & 0.07 & 0.01 & 0.17 \\
$\begin{array}{l}\text { Low pressure } \\
\text { water lines }\end{array}$ & 0.06 & 0 & 0.17 & 0 & 0.47 \\
$\begin{array}{l}\text { High pressure } \\
\text { water lines }\end{array}$ & 0.33 & 0.27 & 0.35 & 0.50 & 0.23 \\
\begin{tabular}{l} 
Flow lines \\
\hline
\end{tabular} & 0.57 & 0.64 & 0.48 & 0.36 & 0.39 \\
\hline
\end{tabular}

One can see that the leak rate first increases during pipe operation and then decreases markedly. For example, the number of leaks on oil gathering systems at PU "Center" for pipes operated for up to five years amounted to 0.23 per kilometer of pipe length in 2004 . With longer pipe operation, namely, 5-10 and 10-15 years, the leak rate increased to 1.23 
and 2.65 leaks per kilometer, respectively, i.e. more than tenfold. Subsequent operation of pipes was accompanied by an abrupt decrease in the leak rate.

Table 2. Leak data for the main OFP types belonging to TNK-BP's BU "Orenburg-Saratov" (PU "South") for 2004.

\begin{tabular}{lccccc}
\hline & \multicolumn{5}{c}{ Number of leaks per 1 km of OFP for pipes operated for: } \\
\cline { 2 - 6 } OFP type & up to 5 years & $\mathbf{5}$ to 10 years & $\mathbf{1 0}$ to $\mathbf{1 5}$ years & $\mathbf{1 5}$ to 20 years & $\begin{array}{c}\text { above 20 } \\
\text { years }\end{array}$ \\
\hline $\begin{array}{l}\text { Oil gathering } \\
\text { systems }\end{array}$ & 0 & 0.63 & 4.25 & 0.59 & 0.43 \\
$\begin{array}{l}\text { Pressurized } \\
\text { pipelines }\end{array}$ & 0.10 & 0 & - & 1.47 & 0.07 \\
$\begin{array}{l}\text { Low pressure } \\
\text { water lines }\end{array}$ & 0 & 0 & 0.99 & 0.70 & 0.65 \\
$\begin{array}{l}\text { High pressure } \\
\text { water lines }\end{array}$ & 0.01 & 0.54 & 0.70 & 0.31 & 0.31 \\
\begin{tabular}{l} 
Flow lines \\
\hline
\end{tabular} & 0.51 & 0.67 & 0.67 & 0.23 & 0.60 \\
\hline
\end{tabular}

The leak rate had a peak at 5-10 years of operation life for pressurized pipelines and flow lines and at 15-20 years for high pressure water lines. Like for oil gathering systems, longer operation of these OFPs resulted in a decrease in leak rate.

Similar dependences with maxima are also characteristic of OFPs at PU "South". An almost threefold decrease in leak rate following a maximum for pipes operated for 5-15 years was observed for flow lines. An even more abrupt decrease in the leak rate was observed in oil gathering systems.

Similar time dependences with extremums were also noted previously, e.g., in $[3,4]$. However, they were always considered as exceptions from the general rule of increasing leak rate.

Still, the data presented here indicate that a distinct trend exists: the leak rate at OFPs that are not subject to special corrosion protection measures first increases with operation time and then decreases markedly. This fact should be taken into account in estimation of the efficiency of OFP corrosion protection measures (for example, by means of corrosion inhibitors). It becomes clear that a decrease in the leak rate, even if considerable, is far not always a consequence of these measures. On the other hand, an increase in the leak rate can accompany measures that noticeably decrease the inside and/outside corrosion rates. 


\section{References}

1. I.S.Sivokon, Korroziya “Territorii neftegaz”, 2008, no. 1, 50 (in Russian).

2. V.R. Amirov and I.S.Sivokon, Territoriya Neftegaz, 2013, no. 10, 56 (in Russian).

3. V.A.Ostreikovskii and Ya.V.Silin, Neftegazovoe delo, 2008, http://www.ogbus.ru/authors/Ostreikovskiy/Ostreikovskiy 1.pdf (in Russian).

4. A.V.Kosov, Vestnik Tomskogo gos. univ., 2009, no. 322, 261 (in Russian).

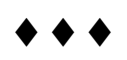

